\title{
OBITUARY
}

\section{MR. RICHARD LAKE}

MR. RICHARD LAKE, F.R.C.S., who was for long a prominent surgeon in London, specializing in the ear, nose and throat, died in a nursing home at Bristol recently, at the age of 87 .

The son of Mr. Thomas Lake, he was born at Sittingbourne, Kent, on December I4th, I86I, and studied at St. Thomas's Hospital. Having qualified M.R.C.S., L.R.C.P., in I885, he took part in the Sudan campaign of that year as a surgeon of the National Aid Society, before the organization of the Red Cross, and then performed similar work in the Servo-Bulgarian war, for which he was decorated by both the Servian and Bulgarian Governments. After his return to England he became F.R.C.S. by examination and began to specialize on the ear, nose, and throat. In I897 he was appointed surgeon laryngologist to Mount Vernon Hospital, and in the course of the next year began his long service with the Royal Ear Hospital (later merged in University College Hospital).

He was president of the otological section of the Royal Society of Medicine in I9I3, and for four years from I924 Geoffrey E. Duveen Lecturer on Otology in the University of London. For many years he was consulting surgeon for diseases of the ear, nose, and throat to a number of hospitals, including University College Hospital and the Seamen's Hospital. He made numerous contributions to the literature of aural surgery, particularly with regard to the surgery of the labyrinth of which he was one of the earliest pioneers.

He was twice married, first to Mildred, daughter of Mr. Justinian Pelly, by whom he had a daughter, and secondly to Ellen, daughter of Mr. George Sapsworth. 